\title{
Orientação sobre o uso de vitamina A na saúde escolar: comparação de técnicas pedagógicas
}

\author{
Orientation on the use of vitamin A in school health: \\ comparision of pedagogical techniques
}

Walnéia Aparecida de Souza 1

Olinda Maria Gomes da Costa Vilas Boas 1

1 Departamento de Farmácia, Escola de Farmácia e Odontologia de Alfenas, Centro Universitário Federal, Efoa/Ceufe.

Rua Gabriel Monteiro

da Silva 714, 37130-000,

Alfenas MG.

walne@int.efoa.br
Abstract Compare the efficiency teaching techniques with respect to their ability to motivate children in the assimilation of the importance of foods rich in vitamin $A$ and the consequences of the absence of these nutrients for the organism. A didactic material comprising two pedagogical techniques was drawn up: one was based on a text with literary connotation and the other with theater marionettes. The study was developed by third grade students in an elementary schoolEscola Municipal Orlando Paulino da Costa (local governement school) - located in the rural area of Alfenas, Minas Gerais, by applying questionnaires. Results demonstrated that the pedagogical techniques used provided learning of concepts related to vitamin $A$ and that they incentivated the consumption of food products containing this vitamin. No significant differences were detected between the pedagogical techniques (Proportion Comparison Test, with $p<0.05)$, since they both make the use of the same methodological principles. We conclude that the application of playing methods was a stimulus to nourishing education. Thus, we propose to use these resources in schools so that children can learn health and nourishment issues.

Key words Vitamin A, Hypovitamin A, School health, Education
Resumo O trabalho tem por objetivo comparar a eficácia de técnicas de ensino em motivar a criança em assimilar a importância dos alimentos ricos em vitamina $A$, e as conseqüências da falta desses nutrientes para o organismo. Foi elaborado material didático com 2 técnicas pedagógicas: uma baseada em um texto de conotação literária e outra, em teatro de fantoches. O estudo foi desenvolvido com alunos da 3 a série do ciclo básico da Escola Municipal Orlando Paulino da Costa, na zona rural de Alfenas, através da aplicação de questionários. Os resultados demonstraram que as técnicas pedagógicas empregadas promoveram aprendizagem de conceitos em relação à vitamina $A$ e incentivo para o consumo de alimentos ricos nesses nutrientes. Não se verificaram diferenças significativas entre as técnicas pedagógicas (Teste de Comparação das Proporções, com $p<0,05)$, uma vez que ambas utilizam os mesmos princípios metodológicos. Concluímos que a aplicação de métodos lúdicos é um incentivador para a reeducação alimentar. Propõe-se, então, o uso desses recursos nas escolas para a aprendizagem de conteúdos de saúde e alimentação.

Palavras-chave Vitamina A, Hipovitaminose A, Saúde escolar, Educação 


\section{Introdução}

Estima-se que milhares de crianças no mundo apresentam deficiência de vitamina $A$. Esta deficiência pode levar à cegueira ou mesmo à morte. $\mathrm{O}$ fato, associado com outras formas de desnutrição, será provavelmente um dos grandes problemas a serem enfrentados após o ano 2000. A extensão da gravidade é imensa e a necessidade de medidas drásticas se faz urgente (Rowell, 1993).

Estudos realizados em vários países têm demonstrado que a deficiência de vitamina $A$ ainda está associada ao desmame precoce, ao consumo inadequado de alimentos fontes de vitamina $A$ pré-formada ou carotenóides e também a pobreza e tabus alimentares, que levam a um consumo inadequado desses nutrientes (Prado, 1995).

Estudos de Niskier (1990) indicam a importância da qualidade alimentar para o amadurecimento das estruturas neurológicas que favorecem o processo de aprendizagem. As crianças brasileiras, em geral, chegam à escola com problemas de desnutrição crônica. Se elas não adquirem, nos seus primeiros anos de vida, os 10 bilhões de neurônios necessários à constituição adequada do cérebro, terão, com certeza, dificuldades de passar pela etapa de alfabetização a partir dos 6 anos de idade. Além disso, existe um fator fundamental que é a visão. Mantê-la de boa qualidade é vital para o desenvolvimento adequado do processo de aprendizagem escolar.

A mudança dietética é um processo gradual, iniciado pela educação. Ela requer, porém, o conhecimento prévio do valor nutritivo dos alimentos; no caso, não apenas o teor correto dos alimentos fonte de vitamina $A$; mas também, daqueles ricos em nutrientes que interagem com esta vitamina durante seu metabolismo ou influem na sua biodisponibilidade, como as gorduras, proteínas ou zinco. Requer, ainda, avaliação da ingestão dietética da vitamina $A$ e conhecimentos dos processos para evitar perdas no processamento culinário. A educação nutricional é medida que pode e deve ser iniciada na pré-escola, prolongando-se no 1 o grau. As oportunidades oferecidas pelos diversos segmentos do currículo devem ser aproveitadas, intercalando-se atividades teóricas de nutrição com práticas de horticultura, culinária e degustação, através da merenda escolar (Roncada, 1992).

$\mathrm{Na}$ escola, os professores têm condições de pôr em marcha programas de educação nutri- cional, promovendo, em nível escolar e familiar, a produção e o consumo de alimentos de origem animal e vegetais ricos em vitamina $A$. No meio rural, em especial, pode-se despertar o interesse das famílias sobre os fatores determinantes da hipovitaminose $A$ e a melhor maneira de combatê-la, a qual se faz pela produção de alimentos que são fontes da vitamina em questão, realizando seu processamento culinário correto sem perda significativa do nutriente (obedecendo, sempre, os hábitos alimentares e a cultura local) e, o principal, seu consumo pelos indivíduos mais expostos ao risco da deficiência (Roncada, 1992).

Mesmo que no Brasil não tenhamos dados suficientes para podermos verificar a intensidade da carência de vitamina $A$ entre nós, existem evidências de que, em algumas regiões do país, a hipovitaminose $A$ constitui problema de saúde pública.

Considerando, então, a relevância das pesquisas realizadas no âmbito internacional e, partindo da hipótese de que esta cena nutricional estaria se repetindo na população brasileira de baixa renda, bem como, considerando a importância da educação em saúde para a mudança da situação, foram desenvolvidos estudos sobre métodos de ensino e experimentos realizados no campo da educação nutricional, com o objetivo de introduzir conceitos em relação à vitamina $A$ e sua carência e, também, propiciar o conhecimento de alimentos que contêm esta vitamina.

\section{Material e métodos}

Local e período de estudo: este estudo foi realizado no período de abril a outubro de 1997, na Escola Municipal Orlando Paulino da Costa, no município de Alfenas(MG)

População estudada: foram selecionadas duas turmas homogêneas da 3 a série do primeiro grau, cuja faixa etária estabelecida foi de 9 a 14 anos de idade. A maioria dos alunos reside na zona rural, possui uma situação socioeconômica insatisfatória e em geral apresenta uma família numerosa.

\section{Instrumentos utilizados}

- Foram elaborados questionários adequados à linguagem e à série analisada, para obtenção de dados da amostra de escolares referentes à 
situação socioeconômica, características da habitação, cultivo de hortaliças ou árvores frutíferas em suas casas, ingestão de medicamentos e conhecimentos prévios sobre hipovitaminose $A$.

- Um texto infantil denominado "O feitiço de Zezinho”, escrito por Souza (1997), ilustrado por A. P. Goulart, baseado no texto, "O Feitiço da Lagoa”, escrito por Schall et al. (1987) foi utilizado como material experimental. $\mathrm{O}$ texto em verso (do tipo cordel) conta a história de um menino doente e fraquinho que não gostava de comer hortaliças, frutas, leite e ovos. Levado ao médico, esclarecido sobre a doença e curado, retorna à escola e torna-se um menino saudável e inteligente. Este texto em quadrinhos foi entregue em preto e branco a cada aluno, possibilitando que ao colorir eles assimilassem melhor o conteúdo. Após a leitura do texto, foram realizadas indagações sobre o assunto focalizado para verificar o grau de aprendizagem dos escolares (Figura 1).

- Um teatro de fantoches intitulado O reino da vitamina $A$, que narra a história de um reino onde as plantações foram amaldiçoadas por uma bruxa e todas as crianças passaram a ter carência de vitamina $A$. Após a encenação, as crianças foram argüidas para verificar se houve assimilação do que foi transmitido.

- Elaboração de panfletos educativos para orientação das crianças em relação à vitamina A. O panfleto foi baseado no modelo do Unicef, Projeto Nordeste, intitulado "Previna-se contra a carência de Vitamina $A$ ". No folheto estão os alimentos ricos em vitamina $A$, as causas de sua carência e como combatê-las. Cada criança, depois da aplicação dos questionários do pós-teste, recebeu um folheto, que foi lido e as dúvidas, sanadas.

\section{Procedimentos}

\section{1ạ etapa: Aplicação de questionários}

Após a entrega dos questionários, as crianças receberam orientações prévias e explicação de que as respostas não seriam utilizadas para avaliação do rendimento escolar. Os questionários funcionariam inicialmente como um préteste, adequado aos estudos, nos quais seria necessário obter uma medida anterior ao tratamento experimental o que poderia funcionar como uma variável independente em si e alte-

Figura 1

Capa e parte principal do texto infantil "O feitiço de Zezinho" sobre hipovitaminose A, utilizada como material experimental.
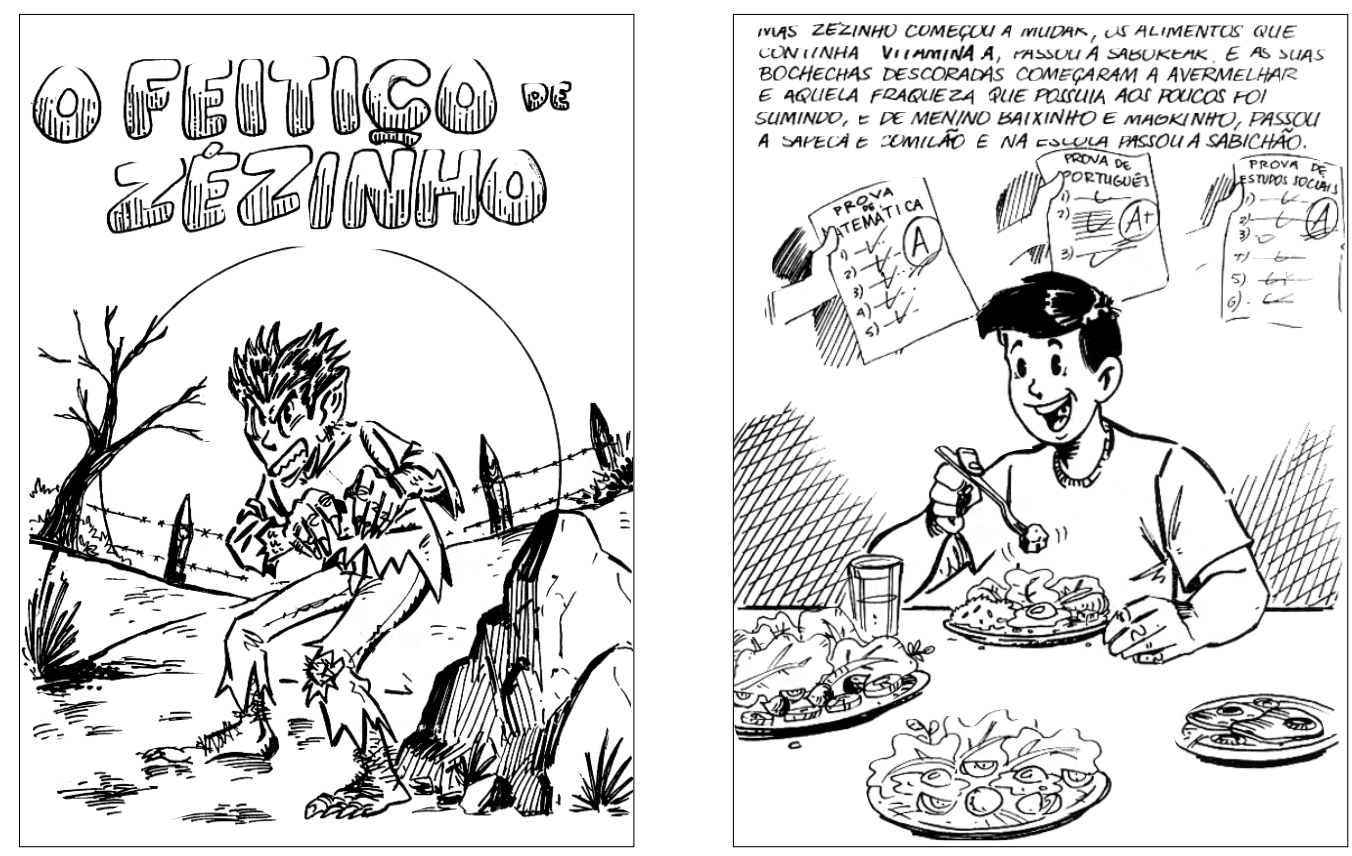
rar os resultados, já que os alunos entrevistados anteriormente poderiam ficar mais atentos às aulas sobre $o$ assunto $e$ apresentariam melhores rendimentos.

\section{2a etapa: Realização do trabalho experimental}

O trabalho experimental constou da aplicação de duas técnicas pedagógicas. A primeira técnica, o texto infantil, foi aplicada em uma das turmas experimentais, e a segunda técnica, o teatro de fantoches, foi aplicada em outra turma.

\section{3a etapa: Aplicação dos questionários posteriores}

Os questionários foram aplicados, um mês após a 2a etapa, aos mesmos escolares submetidos ao pré-teste. Nessa etapa foram repetidas as questões do questionário anterior relativas ao conhecimento da hipovitaminose $A$, suas causas e consequiências. Os dados da amostra foram comparados aos da amostra do questionário anterior, a fim de verificar se o pré-teste poderia funcionar como variável interveniente no processo de aprendizagem, e qual das duas técnicas utilizadas foi a mais eficaz na assimilação dos conhecimentos.

\section{4a Etapa: Distribuição do folheto sobre vitamina $A$}

Com o objetivo de fixar os conteúdos demonstrados na literatura em quadrinhos ou na apresentação teatral, foi distribuído e comentado um folheto com uma súmula sobre a importância da vitamina $A$ para a saúde.

\section{Resultados}

A aplicação de duas técnicas pedagógicas em grupos de alunos pertencentes à mesma série escolar, com semelhanças etárias e socioeconômicas, nos levou a classificar os grupos analisados em dois tipos: grupo do teatro e grupo da história. Os resultados foram analisados estatisticamente, empregando-se o Teste de Comparação das Proporções, EPIDAT (1994).

Ao indagar, "Você sabe o que significa hipovitaminose $A$ ?", foram verificadas diferenças significativas entre o pré-teste e o pós-teste teatro. A história não apresentou diferenças signi- ficativas entre o pré-teste e o pós-teste. Ao comparar as técnicas história e teatro entre si, também não houve diferenças em termos proporcionais, após análise estatística (Tabela 1).

Com relação à pergunta, "Você sabe de alguma pessoa ou de alguma região onde ocorre à falta desta vitamina?", verificou-se que no pré-teste nenhuma resposta foi afirmativa. Já, após aplicação do pós-teste, verificaram-se diferenças estatísticas significativas entre o préteste e o pós-teste.

A análise estatística também demonstrou não existir diferenças significativas entre as técnicas do teatro e história (Tabela 2).

Foram realizadas indagações a fim de verificar se as crianças tinham algum conhecimento sobre os alimentos de origem animal e vegetal, que continham vitamina $A$. Verificou-se que entre os alimentos de origem animal, fígado e ovos, apresentaram uma maior proporção de respostas afirmativas após aplicação das técnicas de ensino, portanto ficou comprovada a diferença estatística entre pré-teste e pós-teste. Quanto ao peixe, manteiga e leite não houve diferenças proporcionais após análise estatística efetuada entre o pré-teste e pós-teste. Apenas as respostas em relação ao queijo apresentaram diferenças significativas entre o pré-teste e a técnica da história. Os resultados estão demonstrados na tabela 3 .

As hortaliças, como cenoura, tomate, pimentão, alface e espinafre não apresentaram diferenças proporcionais entre o pré-teste e o pós-teste. A abóbora e vagem já demonstraram diferenças proporcionais entre pré-teste e pósteste após aplicação da análise estatística. A couve apresentou diferenças estatísticas apenas entre o pré-teste e o pós-teste teatro. Não houve diferenças proporcionais entre teatro e história após análise estatística (Tabela 4).

As frutas, como goiaba e manga, não apresentaram diferenças proporcionais entre o préteste e pós-teste. O mamão e o melão apresen-

\begin{tabular}{lccc}
\hline \multicolumn{3}{l}{ Tabela 1} \\
Você sabe o que significa hipovitaminose A? \\
\hline Respostas & Pré-teste (\%) & \multicolumn{2}{c}{ Pós-teste (\%) } \\
& & Teatro & História \\
\hline Sim & 39,39 & $76,47^{\star}$ & 43,75 \\
Não & 60,61 & 23,55 & 56,25 \\
Total & 100,00 & 100,00 & 100,00 \\
\hline$*(p<0,05)$ Pós-teste $x$ Pré-teste & &
\end{tabular}

Tabela 1

Você sabe o que significa hipovitaminose A?

* $(\mathrm{p}<0,05)$ Pós-teste $x$ Pré-teste 
taram diferenças proporcionais após análise estatística entre o pré-teste e o pós-teste. No teatro, o mamão apresentou $100 \%$ de respostas afirmativas. Os dados estão demonstrados na tabela 5 .

Pela tabela 6, podemos verificar que as crianças apresentaram um determinado conhecimento em relação às doenças causadas pela hipovitaminose $A$, pois diferenças proporcionais entre pré-teste e pós-teste só apareceram nos itens "ossos fracos"; "deixa sem proteção a parte transparente dos olhos" e "a criança apresenta dificuldades para enxergar em lugares escuros”. Quanto às duas técnicas, não houve diferenças proporcionais significativas após análise estatística.

Os estudos realizados, com uma das turmas da 3a série, demonstraram que 93,75\% dos alunos concordaram que a história "O feitiço de Zezinho" contribuiu para a aprendizagem sobre a vitamina $A$. Dos outros alunos da 3 a série que foram entrevistados, verificou-se que 100\% acharam que o teatro de fantoches "O reino da vitamina $A$ " contribuiu também para a aprendizagem de conceitos, doenças e dos alimentos ricos em vitamina $A$.

\section{Discussão}

O trabalho realizado com os escolares da Escola Municipal Orlando Paulino da Costa permitiu verificar que a maioria das crianças não faz uso de alimentos fonte de vitamina $A$, principalmente de origem vegetal. Por isso torna-se relevante reforçar a educação nutricional através de campanhas que possam atingir também toda a comunidade. Algumas intervenções já foram evidenciadas. Por exemplo, na Índia usaram fontes de $\beta$ caroteno no controle da deficiência de vitamina $A$ em pré-escolares e escolares de 7 a 12 anos de idade, de baixo nível socioeconômico, com ingestão inadequada de vitamina $A$, constatando melhoras no quadro geral da hipovitaminose $A$. Também, em um trabalho realizado por Roncada (1992), foi verificado que a ministração de cenoura, espinafre e mamão, como suplemento alimentar, por cerca de um mês, foi suficiente para observar aumento significativo nos níveis sangüíneos de vitamina $A$ nas crianças estudadas.

Outro exemplo bem-sucedido, este em nível nacional, foi o verificado por Mariath et al. (1989), que testaram a eficácia e aceitação da distribuição de doces de buriti às crianças com

\section{Tabela 2}

Você sabe de alguma pessoa ou de alguma região em que ocorre a falta desta vitamina?

\begin{tabular}{lccc}
\hline Respostas & Pré-teste (\%) & \multicolumn{2}{c}{ Pós-teste (\%) } \\
& & Teatro & História \\
\hline Sim & 0 & $35,29^{*}$ & $50,00^{*}$ \\
Não & 100,00 & 64,71 & 50,00 \\
Total & 100,00 & 100,00 & 100,00 \\
\hline
\end{tabular}

* $(\mathrm{p}<0,05)$ Pós-teste x Pré-teste

Tabela 3

Alimentos de origem animal.

\begin{tabular}{lccc}
\hline Alimentos & Pré-teste (\%) & \multicolumn{2}{c}{ Pós-teste (\%) } \\
& & Teatro & História \\
\hline Leite & 81,81 & 94,11 & 81,63 \\
Ovos & 48,48 & $94,11^{\star}$ & $62,50^{\star}$ \\
Fígado & 27,27 & $82,35^{\star}$ & $56,25^{\star}$ \\
Peixe & 30,30 & 52,94 & 56,25 \\
Manteiga & 21,21 & 29,41 & 12,50 \\
Queijo & 24,24 & 47,05 & $62,50^{\star}$ \\
\hline
\end{tabular}

* $(\mathrm{p}<0,05)$ Pós-teste $x$ Pré-teste

Tabela 4

Alimentos de origem vegetal.

\begin{tabular}{lccc}
\hline Alimentos & Pré-teste (\%) & \multicolumn{2}{c}{ Pós-teste (\%) } \\
& & Teatro & História \\
\hline Cenoura & 84,84 & 100,00 & 100,00 \\
Tomate & 60,60 & 58,82 & 75,00 \\
Vagem & 36,36 & $76,47^{\star}$ & $81,25^{\star}$ \\
Abóbora & 48,48 & $94,12^{\star}$ & $93,75^{\star}$ \\
Pimentão & 27,27 & 52,94 & 56,25 \\
Alface & 84,84 & 76,47 & 100,00 \\
Espinafre & 57,57 & 64,70 & 75,00 \\
Couve & 69,69 & $94,11^{\star}$ & 87,50 \\
\hline
\end{tabular}

* $(\mathrm{p}<0,05)$ Pós-teste $\mathrm{x}$ Pré-teste

\begin{tabular}{lccc}
\hline $\begin{array}{l}\text { Tabela } 5 \\
\text { Frutas. }\end{array}$ & \multicolumn{3}{c}{} \\
\hline Frutas & Pré-teste (\%) & \multicolumn{2}{c}{ Pós-teste (\%) } \\
& & Teatro & História \\
\hline Mamão & 69,69 & $100,00^{\star}$ & $93,75^{\star}$ \\
Manga & 63,63 & 58,82 & 68,75 \\
Melão & 36,36 & $76,47^{\star}$ & $81,25^{\star}$ \\
Goiaba & 66,66 & 52,94 & 87,50 \\
\hline
\end{tabular}

${ }^{*}(\mathrm{p}<0,05)$ Pós-teste x Pré-teste 
Tabela 6

O que a falta de vitamina A pode causar na criança?

\begin{tabular}{lccc}
\hline Doenças devido a hipovitaminose A & Pré-teste (\%) & \multicolumn{2}{c}{ Pós-teste (\%) } \\
& & Teatro & História \\
\hline Infecção & 42,42 & 52,94 & 56,25 \\
Anemia & 42,42 & 70,59 & 56,25 \\
Ossos fracos & 48,48 & $82,35^{\star}$ & $87,50^{*}$ \\
Prejudica o crescimento & 48,48 & 70,50 & 68,75 \\
Deixa sem proteção a córnea & 36,36 & $82,35^{*}$ & $81,25^{\star}$ \\
Risco aumentado de morte por desnutrição & 54,54 & 82,35 & 87,50 \\
Dificuldade de enxergar à noite & 48,48 & $94,11^{\star}$ & $82,50^{*}$ \\
\hline
\end{tabular}

${ }^{*}(\mathrm{p}<0,05)$ Pós-teste $\mathrm{x}$ Pré-teste

sinais de xeroftalmia inicial no Nordeste, obtendo regressão parcial ou completa dos sinais clínicos, depois de 20 dias da suplementação, sugerindo que é possível a utilização do buriti em programas de intervenção e combate à deficiência de vitamina $A$, onde a fruta é disponível ou tem possibilidades para o seu cultivo. Muitos outros trabalhos poderiam ser citados. O importante, porém, é registrar que intervenções dietéticas são bem aceitas e trazem resultados positivos. E que o aumento do consumo de fontes acessíveis de vitamina $A$, especificamente dos carotenóides pró-vitamina $A$ em amarelo, laranja e plantas verdes, tem promovido, em longo prazo, minimização da carência. Sua aceitação depende, porém, em grande parte, da conscientização da população-alvo, que se dá pela educação nutricional (Solomons e Bulux, 1993).

A orientação para o aumento da ingestão de vitamina $A$ pode representar uma saída para melhorar a sobrevivência infantil no mundo em desenvolvimento. A administração de vitamina $A$ é uma intervenção simples e de baixo custo, capaz de salvar a visão de milhões de crianças vulneráveis do mundo (Sommer e Tarwotjo, 1984). Mas para o combate à deficiência de vitamina $A$, além de intervenções usuais, seria necessário implementar esforços para a modificação dos hábitos alimentares das famílias, incentivando o consumo de alimentos ricos em vitamina $A$, que são disponíveis em nosso país, além de serem mais baratos (Mariath et al., 1989).

Pela análise dos questionários, verificou-se que as famílias dos alunos desta escola apresentam baixa condição socioeconômica, e não fazem uso do espaço onde residem para plantar árvores frutíferas e hortaliças. Seria necessário que as famílias fossem orientadas no sentido de aproveitarem melhor o espaço. Segundo Rodrigues (1988) essa orientação tem sido realizada em alguns locais. Aumentando-se o consumo de alimentos ricos em carotenóides, assegurase também o maior consumo de outros nutrientes como vitamina $C$, vitaminas do complexo $B$, ferro, potássio, magnésio e outros minerais indispensáveis ao equilíbrio orgânico.

Também, poderia haver a participação dos professores nos passeios no campo para estudar a vegetação local, visitar supermercados, feiras livres, onde fossem vendidos esses produtos. E o refeitório da escola, onde houvesse, seria o laboratório, no qual os princípios aprendidos seriam colocados em prática. Nesse refeitório, os alimentos ricos em vitamina $A$ e em outras vitaminas deveriam ser introduzidos; principalmente os de origem vegetal, que são alimentos baratos e poderiam ser plantados na própria escola, pois estando na zona rural, a maioria apresenta espaço físico considerável. As crianças poderiam cultivar as hortaliças que seriam utilizadas para a sopa, e assim estariam descobrindo o seu próprio meio.

Hoje, existem métodos alternativos de ensinar saúde na escola, além dos puramente expositivos, como ocorre com os métodos tradicionais (Carelli e Olivi, 1992). O cantar, ouvir e ler histórias nada mais é do que uma forma a mais de se estimular o potencial crítico da criança. É levá-la a pensar, duvidar, perguntar-se, questionar e sentir-se inquieta, atiçada (Ramos, 1995).

As observações de relatos de histórias e teatro são técnicas que facilitam o exercício da decodificação de imagens, utilizadas com o objetivo de estimular a descrição de fatos e acontecimentos seqüenciais, possibilitando a associação de causa e efeito. Na literatura nacional há vários exemplos criativos do uso dessas técnicas. Neste trabalho foram utilizadas estas técni- 
cas, certificando-se de que foram incentivadoras no processo de aprendizagem sobre vitamina $A$. E, pelos resultados obtidos, verificou-se que ocorreram mudanças significativas de conhecimento em relação aos conceitos de vitamina $A$, alimentos ricos nesta vitamina e doenças causadas por sua carência. Entretanto, observou-se que o pré-teste funcionou como uma variável interveniente, em que o tema focalizado mobilizou a atenção dos escolares, possibilitando um melhor rendimento após aplicação das técnicas pedagógicas.

Existem vários trabalhos relatados na literatura os quais utilizaram estes recursos. $\mathrm{O}$ texto infantil "O feitiço da lagoa”, escrito por Schall et al. (1987), relata a história de um menino sadio que adquire a esquistossomose ao entrar em lagoa contaminada. O texto hoje faz parte da ciranda da ciência e foi proposto como medida para combater a esquistossomose. Um outro foi realizado por Carelli e Olivi (1992). Eles utilizaram como recurso de ensino para a aula sobre piolho a técnica do teatro de fantoches. Os alunos compuseram uma história e confeccionaram os bonecos (Blois e Barros, 1969). Para Garrocho (1990), a arte deve ser utilizada como técnica de ensino para crianças. A escola aberta de Cruz Alta (RS) também usou o teatro como um trabalho de educação e saúde com adolescentes de rua, e os adolescentes encenavam o seu cotidiano nas ruas: Aids, drogas, promiscuidade e gravidez. Ao participarem de cenas que retratam as situações como eles gostariam de ver esclarecidas, ganham a confiança de que podem ajudar a mudar as atitudes e os comportamentos em suas vidas (Brum e Pereira, 1996).
As histórias em quadrinhos exercem um imenso fascínio. Os heróis dessas histórias além de apresentarem características que os tornam facilmente reconhecíveis para os leitores, semelhantes aos mitos, não evoluem. Continuam imutáveis, não se tornam adultos, nunca; não modificam as qualidades básicas que, ao fim de contas, são a razão de ser. Portanto, a história de Zezinho pode promover um crescimento e enriquecimento sadio permanente, pois a sua figura não evoluirá, mas será sempre representativa de uma criança desnutrida e que após a conscientização da importância dos alimentos se torna uma criança bonita, saudável e inteligente.

A educação lúdica, portanto, na sua essência, além de contribuir e influenciar na formação da criança e do adolescente, possibilitando um crescimento sadio, um enriquecimento sadio permanente, integra-se ao mais alto espírito de uma prática democrática como investe em uma produção séria do conhecimento (Brum e Pereira, 1996).

\section{Conclusão}

Podemos concluir que as técnicas pedagógicas empregadas foram eficazes na aprendizagem sobre hipovitaminose $A$, e que apesar dos conhecimentos de alguns alimentos ricos em vitamina $A$, a ingestão desses nutrientes pela população estudada é ainda inadequada. Mesmo que a maioria dos familiares das crianças cultive árvores frutíferas e hortaliças em suas casas, grande parte não faz uso desses alimentos. Talvez em razão de tabus em relação a determinados alimentos e de desinformação a respeito dos seus valores nutritivos. 


\section{Referências bibliográficas}

Blois MM \& Barros MAS 1969. História para fantoches Ed. Ao Livro Técnico, Rio de Janeiro.

Brum Z \& Pereira MA 1996. Educação em saúde enfocando higiene, sexualidade e drogadição junto aos meninos de rua na faixa etária de 11 a 14 anos. $R e-$ vista Brasileira de Enfermagem 9(3):333-342.

Carelli LA \& Olivi ML 1992. Relato de uma experiência em saúde escolar com alunos do magistério. Revista Brasileira Saúde Escolar 2(1):27-31.

Cintra MA 1976. Os métodos ativos e a escola nova, pp. 37-49. In AD Castro et al. Didática para a escola de 1o e 2 o graus. Ed. Instituto Nacional do Livro, São Paulo.

EPIDAT 1994. Analisis epidemiológico de datos tabulados. OPAS (Organização Panamericana de Saúde). Versão 1.

Focesi E 1992. Uma nova visão de saúde escolar e educação em saúde na escola. Revista Brasileira de Saúde Escolar 2(1):19-21.

Garrocho LC 1990. Uma prática para a arte-educação. Revista Sala de Aula 23(3):34.

Mariath JGR, Lima MCC \& Santos LMP 1989. Vitamin A activity of buriti (Mauritia vinifera, M.) and its effectiveness in the treatment and prevention of xerophthalmia. American Journal Clinical Nutrition 49:849853.

Mora JO \& Dary O 1994. Deficiencia de vitamina A y acciones para su prevención y control en América Latina y el Caribe. Boletín de la Oficina Sanitaria Panamericana. 117 (6):519-528.

Nascimento ES \& Rezende ALM 1988. Criando histórias, aprendendo saúde: uma experiência com crianças de classes populares. Editora Cortez, São Paulo.

Niskier A 1990. Escola ou restaurante? Revista Brasileira de Saúde Escolar 1(3/4):41-43.
Prado MS et al. 1995. Hipovitaminose $A$ em crianças de áreas rurais do semi-árido baiano. Revista de Saúde Pública 29(4):295-300.

Ramos RC 1995. Por que contar estórias na sala de aula? Revista Pedagógica 75:32-33.

Rodrigues RSM 1988. Carotenóides com atividade pró-vitamínica A de hortaliças folhosas e suas alterações com o cozimento. Dissertação de mestrado. Faculdade de Ciências Farmacêuticas da USP, USP de São Paulo, São Paulo.

Roncada MJ 1992. A missão do professor de primeiro grau na prevenção da hipovitaminose A. Revista Brasileira de Saúde Escolar 1(314):36-40.

Rowell M 1993. Eradication of vitamin A deficiency with 5 cents and a vegetable garden. Journal Ophthalmic Nurse Technology 12 (5):217-24.

Schall VT et al. 1987. Educação em saúde para alunos de primeiro grau. Avaliação de material para ensino e profilaxia da esquistossomose. Revista de Saúde Pública 21(5):387-404.

Solomons NW \& Bulux J 1993. Plant sources of provita$\min A$ and human nutriture. Nutrition Revews 51(7): 199-204.

Sommer A, Katz J \& Tarwotjo I 1984. Increased risk of respiratory disease and diarrhea in child with preexisting mild vitamin $A$ deficiency. The American Journal Clinical Nutrition 40:1090-1095.

Souza WA 1997. O feitiço de Zezinho, s.1. (Mimeo).

Sucupira ACSL \& Zuccolotto SMC 1988. Os programas de combate a hipervitaminose $A$ : há indicação para o município de São Paulo? Pediatria 10:14-19.

Artigo apresentado em 3/1/2003

Aprovado e 3/3/2003

Versão final apresentada em 29/9/2003 